\title{
Discursos midiáticos e arte urbana: enriquecimento social ou estereotipação? ${ }^{1}$
}

\author{
Media speeches and street art: social enrichment or stereotyping?
}

\author{
Anita Rink ${ }^{2}$ \\ Ione Vasques-Menezes ${ }^{3}$ \\ Marsyl Bulkool Mettrau ${ }^{4}$
}

\begin{abstract}
RESUMO: Os tempos atuais têm como marca a grande circulação de informação. Jornais, revistas e TV são mídias que influenciam a sociedade e produzem subjetividade. Este estudo objetivou investigar como se veicula a informação sobre a arte urbana e os artistas de rua nos jornais impressos. Pretende-se apontar dimensões destas comunicações que fomentam um tipo de produção subjetiva que circula na sociedade sobre a arte urbana. Os dados foram coletados em dois jornais impressos de grande circulação nacional durante o ano de 2013. A análise dos dados foi feita pelo software Iramuteq, relatório Similitude de Palavras. Os resultados sugerem que as mídias apresentaram aspectos de valorização do grafite e desconsideraram o trabalho dos artistas urbanos em suas atuações sociais, ignorando aspectos da sociabilidade e da política gerada nas ruas das cidades. De qualquer forma, embora os movimentos de arte urbana estejam cada vez mais presentes nos grandes centros urbanos, interferindo e modificando o contexto social e a sociedade como um todo, o espaço dado pela mídia para estes movimentos ainda é relativamente pequeno.
\end{abstract}

Palavras-chave: mídia; arte urbana; mudanças sociais; ideologia; subjetividade.

ABSTRACT: In times of large circulation of news, both street art and newspapers are part of a group of elements that may reveal a kind of social subjectivity. This study is aimed to investigating the speech of the media in newspapers to elucidate how it can provide information about street art and urban artists, in order to identify which dimension of these speeches and subjectivity has been produced in society about the street art. The data in this research were collected through Brazilian newspapers of large circulation during the year 2013. The data analysis was made through the Discourse Analysis method and the Iramuteq software with two aspects: the 'cloud' and the 'similarity of words'. Our results suggest that the media praised some aspects of the graffiti art, but ignored the role of the urban artists in the social action, ignoring important aspects of sociability and politics that rise spontaneously in the streets.

Keywords: street art; media; social changes; ideology; subjectivity.

\section{Introdução}

$\mathrm{O}$ que era considerado pela sociedade e pelo Estado, até meados do século XX, como vandalismo ou crime, passou a ser entendido como uma forma de arte urbana, um conjunto semiótico de signos, imagens, movimentos e sinais de comunicação inscritos no cenário urbano e produzidos a partir do olhar do artista de rua. Atualmente estas práticas e produções sociais ainda são pouco estudadas pela Psicologia, talvez pelo fato das ciências ainda não se orientarem

\footnotetext{
${ }^{1}$ Agência fomentadora da pesquisa: CAPES.

${ }^{2}$ Mestre em Psicologia. Doutoranda em Psicologia pelo Programa de Pós-Graduação Stricto Sensu em Psicologia da Universidade Salgado de Oliveira - Rio de Janeiro, RJ, Brasil. E-mail: anitarink9@yahoo.com.br.

${ }^{3}$ Doutora em Psicologia pela UNB. Professora da Universidade Salgado de Oliveira - Rio de Janeiro, RJ, Brasil.

${ }^{4}$ Doutora em Educação pela Universidade do Minho. Professora da Universidade Salgado de Oliveira - Rio de Janeiro, RJ, Brasil.
} 
por ações e conteúdos inscritos no senso comum e que influenciam a sociedade (Santos, 2002). Segundo este autor, existem importantes formas de conhecimento que não entram comumente em pesquisas científicas, porém, que devem ser consideradas, uma vez que participam e conferem sentido à sociedade. Para Marcuse (2009), o conhecimento científico deve desenvolver aparatos e tecnologias que atuem diretamente na sociedade, para que se possam analisar as transformações que ocorrem continuamente. Hoje em dia defende-se a aproximação entre ciência e sociedade, considerando a articulação entre diferentes formas de conhecimento e, acima de tudo, incentivando que a ciência perpasse inúmeras instâncias sociais (Santos, 2002).

Paim, Machado, Scarparo e Pizzinato (2013) discutem a importância de que os estudos acadêmicos contemplem pesquisas sobre como as informações são veiculadas nas mídias, uma vez que estas afetam fortemente a sociedade como um todo. Segundo estes autores, os meios de comunicação têm uma forte influência sobre a atuação dos sujeitos e sobre as mudanças sociais, e podem, inclusive, produzir reorganizações na vida social. Carvalho Neto, Alves e Baptista (2007), complementam este pensamento ao considerarem que na mudança do comportamento não são apenas as representações sobre ele que se modificam, mas também o mundo, que se transforma efetivamente.

São inúmeras as mídias que participam na cultura atual; as mídias oficiais, como TVs, jornais e revistas, e aquelas não oficiais, com inúmeras facetas de visibilidade e atuação no ambiente urbano. A ação dos artistas de rua tem apresentado fatores importantes para se repensar o comportamento social, no que se refere às dinâmicas urbanas em aspectos democráticos (Negri \& Cocco, 2005; Raposo, 2013). Segundo Fernandes (2009), o Brasil ainda se encontra distante de constituir atuações democráticas no que tange ao modelo político e estatal. Estudos consideram, ainda, que a atuação dos artistas de rua nas cidades pode promover novas formas de vínculos sociais (Rink, 2013) e também pode provocar transformações na psique individual e coletiva, uma vez que, de acordo com Guattari (2006), estas produzem uma nova subjetividade.

Para Camino (1996), a construção social da realidade pode se traduzir em lutas ideológicas pelo poder, em que é possível identificar tanto produções sociais de significado (de ordem social), quanto por fenômenos psicológicos (elaboração de significados), em que a sociedade vem a se estruturar por meio de processos cumulativos, interativos e complementares. A produção de significados sociais é relativa a três esferas que se interligam: 1) individual; 2) institucional e 3) assimetria comportamental, esta proveniente de assimetrias grupais. Neste estudo daremos prioridade à vertente institucional compreendida por Camino como discriminação institucional. O objetivo deste estudo é apontar dimensões das informações em jornais que acabam por fomentar um tipo de produção subjetiva que circula pela sociedade com conceitos sobre o que seja a arte urbana. Jornais são alguns dos veículos institucionais que produzem significados sociais, criando regras, influenciando ações e promovendo, implícita ou explicitamente, distribuições de valores a partir da hierarquia social instituída (Deschamps \& Devos, 1993). Estes valores, para Guattari (2006), constituem uma forma de produção de subjetividade.

Este autor dimensiona a subjetividade para além dos termos clássicos, relacionando-a a uma ideia personalista. A subjetividade, portanto, é produzida em esferas individuais, coletivas 
e institucionais. Segundo ele, a organização das cidades feita pelo Estado, por exemplo, é uma forma de produção de subjetividade, e os signos e sinais, como outdoors e sinais de trânsito, participam da paisagem e influenciam o comportamento e o pensamento social. Ou seja, por meio de diversos movimentos, sejam eles individuais, institucionais ou coletivos, produz-se subjetividade.

Em inúmeras cidades, a arte de rua representa uma forma de subversão à estética urbana usual, uma vez que carrega em si uma ética da visibilidade, assim como germes de inconformidade e de resistência (Costa Junior \& Portinari, 2014). A arte urbana tem influenciado a produção de novos sentidos sociais (Furtado \& Zanella, 2009) e, portanto, tem produzido uma nova forma de subjetividade. Por ser feita em um espaço público, a arte de rua além de obter grande visibilidade, apresenta uma infinidade de novas vozes de sujeitos sociais que eram invisíveis até então. Estas múltiplas faces fazem-se presentes no cenário público através da street art, que confere um status democrático às cidades. As atuações destes atores sociais constituem-se em ações, movimentos e produções que criam, acima de tudo, cultura.

Os estudos de Spinelli (2010) consideram a arte de rua através da ótica do grafite como um tipo de linguagem urbana pós-moderna. Para o autor, esta arte tem aspectos que facilitam sua percepção e compreensão pelos transeuntes, uma vez que esta comunicação social tem suas bases na cultura visual de massa, o que facilita com que o cidadão possa atribuir-lhe um significado.

Segundo Rink (2013), a produção de arte urbana geralmente se dá pelo envolvimento de vários atores, tornando-se um trabalho coletivo que fomenta vínculos sociais na esfera pública. Para este autor, a arte urbana tem revelado importantes aspectos nos meios urbanos, seja por meio das variadas relações sociais estabelecidas pelos artistas de rua, seja pela possibilidade de pensar a sociedade, a cidade, a estética e a política por novos prismas. Por este motivo, alguns autores já consideram os estudos sobre arte urbana de extrema relevância social.

Diferentes estudos sugerem que, por meio da arte e do desenvolvimento da sensibilidade estética, muitos fatos sociais e psíquicos podem ser transformados, porque a arte polissêmica estabelece uma rede de diálogos (Mesquita, 2006; Rosanvallon, 2008). Em outras palavras, a arte de rua propicia novas formas de atuação em sociedade. Azoulay (2011) aponta que, por meio da arte da fotografia, por exemplo, existe uma expressão além da estética, que pode ser entendida como uma intenção política envolvida no processo. Mesquita (2006), por sua vez, sugere que a produção artística gera conhecimento autônomo e também relaciona a Educação como uma experiência estética. Este autor estuda as intervenções artísticas no espaço urbano como uma intercessão entre a arte de rua e o ativismo político. Para o autor citado, a arte urbana

... sintetiza o hibridismo entre arte e política, criando territórios de conhecimento, zonas autônomas temporárias e condições de intervenção no contexto urbano, além de propor uma maior liberdade de criação desvinculada do sistema institucional de arte (Mesquita, 2006, p. 9).

O autor considera que intervenções artísticas urbanas sejam uma espécie de ativismo cultural. Para este autor, por meio da educação estética e da produção artística, as pessoas desenvolvem novas posturas pessoais e uma consciência de sua posição na sociedade, e também desenvolvem novas concepções de atuação e reflexão e podem realizar críticas à sociedade na qual estão inseridas. Rink e Will (2015a), por exemplo, apontam que artistas de 
rua são produtores de movimentos de resistência, uma vez que conseguem congregar diversas experiências vividas, vivenciadas em suas reflexões e atuações no espaço urbano.

Com base nos estudos de Rink (2013), o grafite é uma forma de produção cultural e se constitui por meio de vivências carregadas de afeto e de formas singulares de sociabilidade, em que artistas exercem sua criatividade e inventividade estetizando espaços públicos. Muitas modalidades de ações urbanas são consideradas arte urbana, como malabarismos feitos nos semáforos, a música de rua, o skate, o lambe-lambe, o sticker e o grafite. $\mathrm{O}$ artista de rua age sobre a cidade produzindo vozes que se estendem da política à poética. A produção de street art, portanto, é uma das formas de se vivenciar as experiências urbanas em redes de afetos na cidade, onde cada transeunte pode ressignificar estas experiências estéticas, éticas e políticas. Para França (2012), são estas ações e vivências de cada pessoa que podem desafiar o excessivo pragmatismo do sistema capitalista, que atribui determinados valores ao viver, impondo formas do que deve ser dito, feito ou pensado.

Neste contexto, a mídia oficial que também se apresenta como uma forma de produção subjetiva é diferente da arte de rua. Segundo Salles (2008), as mídias, de modo geral, são ideologicamente afinadas e estão a serviço da exploração dos povos para garantir os lucros das corporações privadas mundo afora. Para este autor, as mídias tendem a criar um tipo de subjetividade padronizada, modelada, passiva, obediente e disciplinada.

Coimbra (2009, citado por Will, 2015) acredita que na sociedade contemporânea um dos dispositivos mais importantes para se produzir subjetividade sejam os meios de comunicação de massa. Para o autor, as mídias produzem modos de viver, de pensar e de sentir; em outras palavras, a mídia acaba ditando o que deve ser pensado e sentido. Os estudos de Guareschi (2007) destacam que as conversas que ocorrem na sociedade são pautadas, em sua grande maioria, pela mídia. Este autor analisa o quanto os meios de comunicação estabelecem valores, constroem uma realidade e tornam-se uma agenda de discussão, ou seja, uma poderosa ferramenta na construção de subjetividade.

O autor citado também considera que uma convivência excessiva com os veículos midiáticos pode bloquear a criatividade, criando alienação. Zago (2008) identificou que as redes sociais, como o Twitter, são muito utilizadas para disseminar conteúdos jornalísticos, o que deixa bastante evidente a importância desta rede na produção de subjetividade dos indivíduos.

A subjetividade é produzida continuamente, não podendo ser considerada um atributo inato ao ser humano. Ao contrário, ela é construída em múltiplas esferas, coletivas e institucionais, unidas às vivências pessoais de cada individuo. Por isto, pretende-se investigar que tipo de informação produzida pelos meios de comunicação tem circulado na sociedade. Em outras palavras, de que modo a mídia impressa produz um tipo de conteúdo que fomenta certas produções subjetivas. Para embasar este estudo, encontrou-se apenas uma pesquisa que se aproxima deste tema. Rink (2013) compilou uma década de notícias de jornais sobre a arte do grafite e os grafiteiros, entre os anos 2001 até 2011. Segundo o autor, os jornais brasileiros passaram a se ocupar mais deste tema a partir de 2003, principalmente quando uma grande empresa de moda lançou nas passarelas um novo estilo baseado no grafite.

Existem inúmeras pesquisas que sugerem que há novas atuações dos artistas de rua e uma influência destes na esfera pública, social, cultural e subjetiva. Porém, ainda são escassos 
estudos que analisam este tema a partir da veiculação de conteúdos nos jornais sobre a arte de rua e as dinâmicas artísticas estabelecidas por ela nas cidades. A pequena quantidade de material encontrada sobre o assunto desta pesquisa aumenta a relevância social do presente estudo, assim como seu valor acadêmico, uma vez que visa ampliar as discussões sobre como a mídia apresenta os artistas de rua, analisando quais facetas destes artistas são apresentadas pelos jornais de circulação nacional.

\section{As cidades, seus movimentos e sua relação com a mídia}

Hoje em dia já podemos identificar quais ruas e cidades, do ponto de vista da arte, têm sido local de gestação de diversas experimentações. São aquelas que estão repletas de atividades estéticas e simbólicas de modalidades de arte feitas por diferentes artistas urbanos. Negri e Cocco (2005) consideram que a rua, por ser um espaço comum, possibilita a ocorrência de múltiplas experimentações. Sendo a arte de rua uma faceta destas experimentações, as pessoas podem construir novas ideias e dinâmicas culturais, e, consecutivamente, desenvolver o que estes autores consideram ser uma governança coletiva (ou multitudinária).

Para os autores citados, esta governança multitudinária tem se dado através dos movimentos sociais e intervenções feitas no meio urbano, com a apropriação dos espaços públicos. Estas atuações no meio urbano tendem a gerar mais autonomia nos sujeitos, ou melhor, as pessoas envolvidas nessas atuações passam a ter mais consciência quanto ao lugar que ocupam na sociedade e sua força política (Negri \& Cocco, 2005). As cidades são locais que favorecem a ocorrência de ações autônomas e possibilitam que novas formas de subjetividade sejam produzidas.

As cidades também são lugares em que muitos indivíduos podem se unir em reivindicações de seus direitos, uma vez que existem certas questões comuns a muitas pessoas e ao espaço público. Por exemplo, problemas relacionados aos transportes e aos problemas ecológicos podem tornar-se foco de reivindicações do público. Além disso, questões ligadas à educação, problemas sociais e segurança, ou assuntos relacionados às formas de convivência podem vir a ser temas comuns que estimulam muitas pessoas a buscar exercerem uma atuação política, tanto pessoal como coletiva (Negri \& Cocco, 2005).

As reivindicações do público acabam ganhando visibilidade nas cidades, principalmente quando se apresentam em modo criativo ou artístico. Para Raposo (2013), a participação e o compartilhamento, tornados possíveis por meio do convívio em comunidade, geram trocas de conhecimento e informação. A ação e a circulação de determinados atores sociais nos espaços públicos, além de criarem formas de sociabilidade, modificam esteticamente as cidades (Negri \& Cocco, 2005), fazendo dos muros ilustrados com a arte de rua, uma forma de mídia não oficial, que comunica e revela outras atuações nas cidades (Moura, 2014).

É a possibilidade de experimentar, criar e conviver a partir das vivências nas ruas que pode gerar um novo tipo de aprendizado e mais autonomia aos sujeitos (Negri \& Cocco, 2005), principalmente em relação ao pensamento dominante, influenciado pelo neoliberalismo usualmente reforçado pela mídia. Para estes autores, a cidade é o lugar onde nasce a maioria dos movimentos sociais, sendo ela um local, por excelência, da insurgência de atuações de diversas pessoas e grupos que contribuem para a renovação social. Em qualquer cidade, é 
possível o surgimento de formas de coesão e também de reivindicações, tal como o importante movimento social estadunidense Occupy, citado por Harvey (2013).

As ruas podem ser o "... lugar de encontro, de diferença, e de interação criativa, um lugar onde a desordem tem seus usos e visões, formas culturais e desejos individuais correntes se chocam" (Harvey, 2013, p. 34). Para este autor, mesmo que os espaços urbanos apresentem uma grande concentração do legado do capitalismo neoliberal, acoplados a uma sociedade de controle, também nas cidades pode ocorrer o surgimento das melhores possibilidades de superá-los. Por este motivo o autor acredita que, mesmo que as metrópoles pareçam caóticas ou ordenadas friamente, elas também são as arenas de embates e de transformação da cultura.

\section{Mídia e arte}

Toda mídia é um conjunto de meios de comunicação social, e existem diferentes tipos de mídias, algumas oficiais e outras não. Os jornais e a arte de rua são mídias que se propagam simbolicamente pela sociedade; a primeira é uma espécie de mídia oficial e a segunda não. Ambas, porém, apresentam formas de produções semióticas, que circulam na sociedade atual, influenciando e sustentando dimensões de subjetivação social (Guattari, 2006).

A arte, seja ela arte de rua ou não, pode ser constituída de múltiplas linguagens, algumas de perfil oral ou visual-artístico, porém trata-se de uma atividade simbólica que (re)organiza e muda a atividade psicológica (Vigotski, 2011). A produção de arte é, por isso, uma atividade que lida com uma extensa gama de símbolos sociais e imaginários, que fomenta, inclusive, novos comportamentos.

Pautando-se no pensamento deste autor, a linguagem da arte pode ser considerada para além da comunicação que ela propicia, uma vez que a arte ao longo da história tem produzido inúmeros e diferentes sentidos. A natureza histórica da psique, discutida por Vigostki (2011), abre-se para o conceito da natureza criativa da psique, que também é reforçado por Maturana (2002), que concebe uma existência criativa nas estruturas biológicas. Em outras palavras, Maturana (2002) atribui a um aspecto intrínseco do ser vivo a sua capacidade de 'mudança evolutiva'. Para este autor, o fato do ser humano estar inserido em um ambiente e em um contexto repleto de seres e objetos requer constantes adaptações, uma vez que múltiplas formas de relações são estabelecidas.

Também Csikszentmihalyi (1996) afirma que toda nova criação muda a forma como pensamos e agimos. Os autores citados não baseiam seus estudos em aspectos imutáveis da psique ou da biologia, posto que consideram o meio ambiente e o meio social como agentes que influenciam o sujeito. A psique se constitui e se organiza por meio das atividades humanas e, também, das atividades simbólicas. É através de atuações criativas e artísticas que as transformações culturais são estabelecidas, ou seja, é pela arte e pela criatividade humana que se modificam as atividades psicológicas (Vigostki, 2011).

É corrente na sociedade a ideia de que o jornalismo apresenta e narra de forma objetiva os fatos e notícias. Guimarães (2008), porém, discute o fato dos equipamentos de produção coletiva terem uma orientação específica, que visa dar algum tipo de significação ao mundo. 0 autor considera que a ideia de objetividade jornalística tem pouca fundamentação, uma vez que não existe um instrumento social que seja indiferente ou imparcial. 
Em se tratando de mídias oficiais, como jornais e TVs, Ferreira e Travancas (2014), consideram que as notícias são como um espelho de cada sociedade na qual circulam. Para estes autores, as notícias são construídas por um determinado grupo social e tornam-se representações que orientam a ação social, uma vez que são vividas como algo real, ou seja, as notícias são ponto de "... confluência do social com o individual" (Ferreira \& Travancas, 2014, p. 626).

Segundo Will (2015), a mídia é um conjunto de meios de comunicação que funcionam em rede, refletindo e complementando as mesmas notícias na construção dos discursos homogêneos. Raposo (2013) e Paim et al (2013) complementam essa ideia ao afirmar que as mídias não têm sido veículos para múltiplas vozes sociais, ainda que a cultura popular tenha se tornado objeto de interesse tanto da mídia, quanto de estudiosos. De Certeau (1998) explica as motivações e o forte interesse da mídia pela cultura popular como uma forma de imprimir uma lógica própria. Segundo o autor, isto significa eliminar o perigo de subversão cultural de outros atores e diferentes produções que, de alguma forma, possam ameaçar as classes dominantes.

As produções de signos e símbolos sociais funcionam como vozes de discursos que propiciam a ocorrência de diálogos e interação entre as pessoas (Guattari, 2006). Por este motivo, o autor considera que a produção semiótica social não só sustenta dimensões de subjetivação, mas também as produz. Inúmeros outros autores consideram que qualquer exibição de comerciais e circulação de jornais imprimem e alimentam significados sociais. Para Guattari (2006), portanto, certas produções semióticas de ampla circulação na sociedade afetam fortemente a psique social, já que pertencem ao 'equipamento de produção coletiva' e, por isso, deveriam ser continuamente investigadas.

Sendo a mídia um importante agente que imprime significados diversos à psique humana, estudá-la é socialmente e academicamente relevante, uma vez que ela tende a revelar aspectos sobre como a sociedade e os indivíduos têm se estruturado subjetivamente. Faz-se necessário, portanto, buscar entender se a presença da arte de rua na mídia acaba sendo uma forma de debelar seu potencial subversivo, bem como, se a sua presença na mídia é uma forma de neutralizar suas características políticas e democráticas.

Acredita-se, que como resultado do estudo, serão detectadas formas como as mídias oficiais tendem a ocultar algumas dimensões da arte de rua, como a sua sociabilidade e natureza política. Se a experimentação, a criação e o convívio social nas ruas das cidades propiciam o surgimento de uma forma de governança coletiva, como mencionado por Negri e Cocco (2005), isto significa que estas modalidades de ação podem subverter a ordem vigente na sociedade e na política oficial. Assim, ocultar as dimensões de sociabilidade e natureza política da arte de rua poderia ser uma forma de conter esta proposta de articulação de novos valores na sociedade.

\section{Metodologia: campo de pesquisa}

Utilizou-se o método de estudo documental de caráter exploratório e descritivo com o objetivo de investigar como os jornais impressos veiculam informação sobre a arte de rua e os artistas urbanos. O critério de inclusão foi usar jornais de grande circulação, de edição diária, de alcance nacional, que apresentassem setores variados, tais como política, cultura, economia 
dentre outros. Os jornais analisados foram O Globo e O Estado de São Paulo (Estadão) no período de janeiro a dezembro de 2013. Buscou-se noticias que abordavam a arte de rua e a arte urbana no título ou no corpo do texto da notícia. A simples menção de pessoas ou eventos em espaços urbanos associados à arte urbana ou de rua nos seus conceitos estéticos ou políticos entrou no processo de análise.

O tratamento dos dados foi feito através do Iramuteq (Interface de R pour analyses Multidimensionelles de Textes et de Questionnaires) em análises textuais das palavras. A importância deste software, segundo Camargo e Justo (2013), é o fato de poder fazer pesquisas e estudos que envolvam grande volume de dados textuais a serem analisados. Análises textuais podem ser facilitadas e enriquecidas com a utilização do Iramuteq, uma vez que este "apresenta rigor estatístico e permite aos pesquisadores utilizarem diferentes recursos técnicos de análise lexical, ao campo de estudo das ciências humanas e sociais..." (Camargo \& Justo, 2013, p. 516517). Além das análises lexicais feitas, este programa também possibilita que não "se perca o contexto em que a palavra aparece, tornando possível integrar níveis quantitativos e qualitativos na análise, trazendo maior objetividade e avanços às interpretações dos dados de texto" (Camargo \& Justo, 2013, p. 517). Os dados selecionados foram analisados pelo software e interpretados através do relatório de Similitude de Palavras. Este relatório possibilita identificar as ocorrências entre as palavras, indicando tanto a conexão entre elas, quanto auxiliando na identificação da estrutura da representação (Marchand \& Ratinaud, 2012). Com este resultado, tem-se um arcabouço formal para dados subjetivos que se apresentam através de uma imagem gráfica simples, com um aspecto aproximado de árvore. Este formato favorece uma boa percepção dos resultados.

O primeiro estudo foi feito com os jornais impressos, folheando todos os cadernos dos jornais. A partir dos artigos selecionados, produziu-se um corpus de análise, compondo-se em um único arquivo o conjunto de textos jornalísticos selecionados. Estes textos foram separados por linhas de comando, também chamadas de "linhas com asteriscos", compostas por variáveis categóricas de identificação do artigo de jornal, de acordo com o objetivo da pesquisa, como: 1) modalidades de arte de rua, tais como: grafite, pichação e dança; 2) espaço mencionado: ruas ou locais que segmentavam o público; 3) atores sociais: grafiteiros, dançarinos e outros, e finalmente a 4) composição social dos atores, ou seja, se foram apresentados unitariamente ou em coletivos.

A única modificação feita no texto original foi a substituição das palavras 'street art' e 'arte de rua' por 'arte urbana', por serem estas sinônimas, porém não sendo identificáveis como tal pelo programa utilizado. Foram adicionados dezoito (18) artigos de jornal para análise pelo software e programada a eliminação de artigos definidos e artigos indefinidos, conjunções e preposições. A análise categorizou palavras com frequência entre 50 e 25 repetições. As palavras que se agruparam no relatório de Similitude de Palavras foram sistematizadas através da análise de sentido, assim como tratadas pela análise do conteúdo (Bardin, 2006).

\section{Resultado e discussão}

A análise das notícias dos jornais não só apontou a palavra grafite como tema central, mas também foi verificada a sua articulação em três eixos. Num primeiro eixo, de forma endêmica, a 
palavra grafite (50 repetições) está relacionada à palavra grafiteiro (35 repetições). No segundo eixo, a palavra grafite está relacionada à palavra muro (28 repetições), indicando uma associação prática-funcional. O terceiro eixo, mais interessante, aponta para uma relação mais urbana que associa a palavra grafite às palavras cidade (27), rua (38) e arte (37). Por sua vez, a palavra arte se desdobra em dois sub-eixos: o primeiro mais ligado ao contexto urbano social com as palavras arte (37), espaço (21) e projeto (27).

O segundo sub-eixo, mais associado à expressão artística, urbano-artístico, interliga as palavras arte (37), obra (30), artista (33) e trabalho (38). É interessante ressaltar que a expressão arte urbana analisada de forma composta, tal como é utilizada pelo senso comum, não resultou em evidência significativa, apesar da multiplicidade de expressões artísticas que está associada a ela, indicando que este conceito não é considerado pela mídia escrita.

As outras modalidades de arte de rua como a pichação, muito comum nas cidades, dança de rua, teatro de rua, e malabares também podem indicar, pela sua presença, a crise crescente no mercado de trabalho e a precarização das relações trabalhistas. Estas foram muito pouco contempladas pelos jornais pesquisados, o que corrobora a indicação de Ferreira (2011) e Franco (2013), que afirmam que a mídia nacional tem continuamente rechaçado e desvalorizado outras formas de arte urbana. Segundo estes autores, a arte de rua tornou-se fortemente marcada pela expressão da cultura hip-hop no Brasil após os anos 1980, a qual é composta pelo grafite, pelo rap (poesia fala/cantada), pela dança de tipo break e pela arte dos disc-jockeys, ou DJs. Contudo, nenhuma destas expressões, excetuando-se o grafite, ganhou grande espaço junto às mídias pesquisadas. A centralidade e relevância da palavra grafite no contexto das notícias selecionadas corrobora Blauth e Possa (2012) e Ferreira (2011) que tratam o grafite como uma forma de arte com inserção em diferentes espaços culturais, disponibilizando vários tipos de experiências sociais, educativas e estéticas.

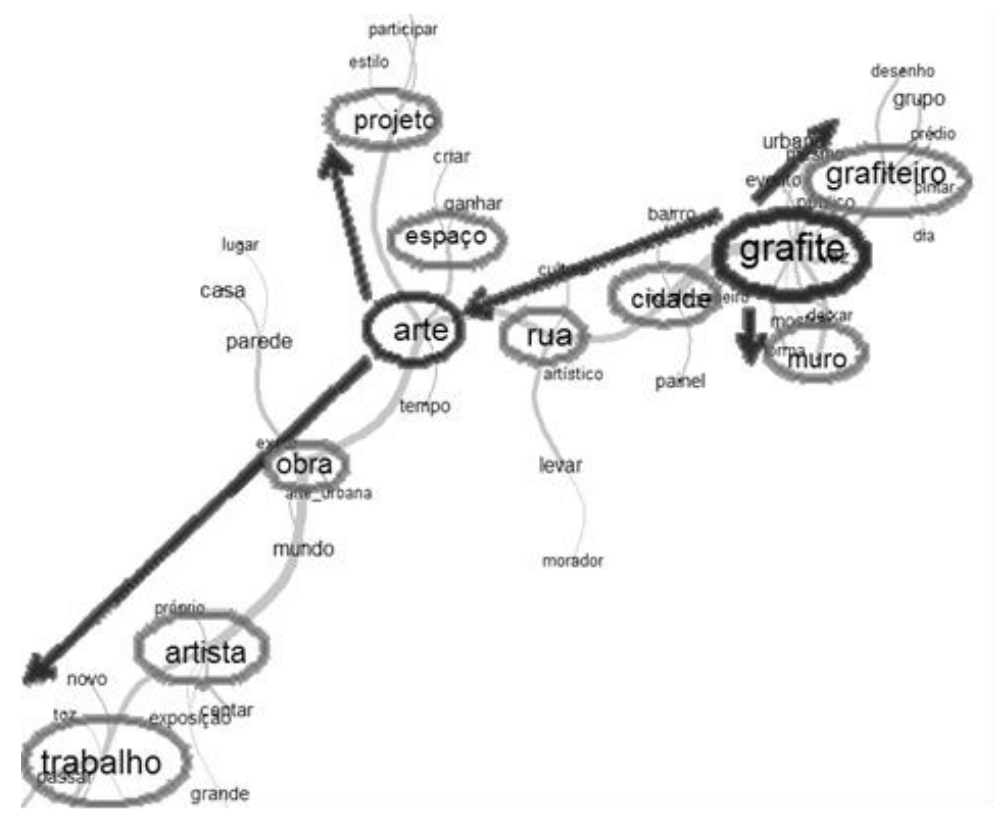

Figura 1 - Similitude de Palavras 


\section{Eixo endêmico e eixo prático-funcional}

Os dois primeiros eixos encontrados no estudo, o eixo endêmico e o eixo prático-funcional serão discutidos em conjunto, em função de suas características e complementaridade. 0 primeiro eixo associa de forma endêmica as palavras grafite e grafiteiro e o segundo eixo associa as palavras grafite e muro, dando-lhes um sentido prático-funcional, ou seja, como o local mais comum de expressão do grafiteiro. Estes eixos podem ser vistos como uma expressão básica do artista de rua, onde se evidencia tanto a obra (grafite), quanto o autor (grafiteiro) e o local (muro).

O segmento de texto (ST) que pode representar estes dois eixos é: “... o maior painel de grafite da cidade, feito por grafiteiro Toz, no porto insônia: no muro do jockey..." (grifo nosso notícia do Jornal O Globo, de 01/02/2013) que representa bem esta articulação entre a obra, o autor e o local. O que chama atenção nestes dois eixos é a não-associação das palavras grafite, grafiteiro e muro num único eixo. Ao separá-las, tem-se a dimensão de desagregação em que os jornais abordam a arte de rua, ora focando no seu autor, ora deslocando-se para o espaço utilizado para a expressão do autor.

Neste segmento de texto apresentado é mencionado um famoso grafiteiro, Toz, que, geralmente é contratado para grafitar muros de grandes dimensões. Porém, segundo Moura (2014), existe uma descaracterização da arte de rua neste tipo de atuação dos grafiteiros e a exposição de grafite feita em grandes dimensões na cidade, uma vez que

termina por "massificar" a "cidade" do ponto de vista de intervenção urbana, contradizendo expressões de liberdades artísticas e as motivações identitárias ou contestatórias que caracterizavam as formas originais de expressão de arte de rua (Moura, 2014, p. 12).

O autor afirma, ainda, que as produções em grande escala de grafite são expressões que servem tanto para a lógica da acumulação como para uniformização espacial, eliminando as diferentes vozes do espaço público. Pequenas intervenções, portanto, são engolidas pela lógica neoliberal. O que é apontado pelo relatório pode ser indicado como resultado das mídias reforçando a ótica neoliberal, ao apresentarem de modo desagregado e fragmentado o autor, a obra e o espaço.

A palavra grafiteiro atrai, embora com baixa frequência de repetição, as palavras prédio (10) e público (14), o que pode sugerir uma relação com outras formas de expressão que buscam deixar sua marca no alto das edificações e nos patrimônios públicos, como a pichação, e que os jornais evitam associar à arte de rua. Em outras palavras, é mais fácil enxergar e divulgar o grafite nas laterais dos prédios e nos muros dos espaços urbanos do que ver estes ambientes pichados, como uma poluição estética das cidades, ou atribuir alguma visibilidade aos atores sociais que as produziram. Para Ferreira (2011), o fato de os pichadores não terem uma visibilidade nas mídias oficiais faz com que estes criem uma enorme escala de repetição dos seus grafismos pela cidade, buscando o desafio de picharem em lugares de difícil acesso, como prédios e monumentos públicos. Neste sentido, prevalece o grafiteiro $e$ as vozes da cultura hegemônica associados de forma tímida e endêmica ao grafite. Isto sugere que o sentido produzido pelos jornais não associa o artista de rua à sua capacidade criativa, uma vez que algumas expressões da sua arte não são apresentadas ou discutidas. Em outras palavras, os sujeitos em suas alteridades são concebidos por pontos de vista fixos, o que os torna, em uma 
visão para a coletividade, incapazes de experimentações ou de ações políticas inéditas (Ortega, 2000). O isolamento da palavra grafiteiro também pode estar ligado ao fato das matérias de jornal não atribuírem valor às ações do coletivo dos grafiteiros e da sua arte de rua, desconhecendo as possibilidades de construção de novas dinâmicas culturais, a partir de atuações grupais no espaço urbano.

A palavra grupo aparece 18 vezes, mas mesmo assim é apresentada na ponta do gráfico, sem grande relevância (vide figura I). Para Rink (2013), o fato dos grafiteiros, de modo geral, fazerem uso de paredes e muros em ações individuais ou coletivas, sem prévia permissão do Estado ou dos proprietários dos locais, pode impedir que estes atores sociais ganhem espaço em um tipo de mídia que é refém dos interesses econômicos dominantes. Pelo isolamento entre obra (grafite), autor (grafiteiro) e local (muro), expresso nestes dois primeiros eixos, podese dizer que a arte de rua é apresentada usualmente pelas mídias impressas de uma forma fragmentada e relacionada às posições hegemônicas.

\section{Eixo urbano}

O terceiro eixo, com uma característica mais urbana, associa a palavra grafite aos contextos da cidade, da rua e da arte e se desdobra em dois sub-eixos, um ligado ao contexto social e outro associado à expressão artística em si. Este eixo e os sub-eixos resumem o espaço dado pela mídia escrita à arte urbana.

O primeiro aspecto a ser ressaltado é a associação, de certa forma esperada, do grafite à cidade, à rua e à arte, reforçando o espaço da cultura hegemônica explorada pela mídia e o caráter essencialmente urbano do grafite. Outro aspecto que deve ser ressaltado é o antagonismo entre as associações entre as palavras grafite-arte e as díades grafite-grafiteiro e grafite-muro.

O distanciamento da díade grafite-arte das díades grafite-grafiteiro e grafite-muro sugerem que as duas últimas se articulam como expressões de não-arte, embora criativas. Segundo Moura (2014), o uso corrente da palavra arte para falar do grafite faz com que exista uma sensação e uma ideia de aceitação social. O grafite-grafiteiro se relaciona mais com grupos específicos e diferem de lugar para lugar, o grafite-muro também pode seguir a mesma lógica, a expressão de cada muro se relaciona às condições locais e socioculturais de seus executores, porém a díade grafite-arte é mais abstrata e pode se referir, por exemplo, a uma linguagem da arte e não a uma atitude de sujeitos em suas especificidades. A divisão de arte em dois subeixos permite também algumas observações interessantes. A primeira, diz respeito às concepções do grafite enquanto movimento artístico, associando-se arte, obra, artista e trabalho, em oposição às associações do grafite enquanto movimento social, menos significativo que o anterior, articulando arte, projeto e intervenção.

A segunda observação, quase um desdobramento da anterior, foca o grafite enquanto expressão individual ou coletiva no espaço urbano como arte, mas destituída do seu papel crítico. Um bom exemplo é o seguimento de texto analisado “... Um grupo de amigos de São Paulo encontrou uma alternativa para trazer um pouco mais de cor para uma cidade" (grifo nosso - Jornal O Globo 31/05/2013, caderno Cultura). Esta frase caracteriza os grafiteiros como 
um grupo de amigos e a expressão critica social do trabalho como mais cor para a cidade, minimizando o poder de produção de diálogos políticos e sociais a partir do impacto produzido pela arte do grafite. Negri e Cocco (2005) consideram que ações individuais ou coletivas no espaço comum da rua podem construir novas ideias e dinâmicas culturais e, consecutivamente, provocar mudanças no que já está posto.

A mídia analisada ao associar o grafite como uma expressão artística, na sequência arteobra-artista-trabalho, sub-eixo do movimento artístico, o faz de forma geral, privilegiando o valor individual ao grupal. Às vezes evidencia o já consagrado, como no segmento de texto: "O grafiteiro Toz ganha álbum retrospectivo depois de ser valorizado pelas galerias Tomaz Viana..." (Grifo nosso - Jornal O Globo, 21/04/2013, caderno de bairro: Rio). Outras vezes reconhece a rua como lugar de produção cultural, trazendo para os espaços privados uma forma de valorizar e aproximar essas produções da sociedade, como nos segmentos de texto "... a mostra na galeria agora nos faz entrar em outro momento e pensar como levar o trabalho de volta às ruas..." (grifo nosso - noticia do Jornal O Globo, de 22/08/2013, caderno: Cultura) ou "além das galerias de arte que já valorizavam adeptos do gênero há algum tempo, cada vez mais lojas de roupas e produtos comprovam que o design e a moda estão mesmo juntos e misturados com o grafite" (grifo nosso - noticia do Jornal O Globo, de 17/11/2013, caderno: Ela, Moda).

Em outro trecho pode-se perceber esta transição do grafite como arte marginal para arte de interesse de grupos econômicos e culturais mais elitizados em espaços mais restritos das galerias de arte: "Ricardo [marchand de alguns grafiteiros] foi o responsável pela transposição do trabalho do grafiteiro Toz para a galeria..." (Jornal O Globo, 26/03/2013) ou neste outro segmento de texto

É legal oferecer a arte dele [grafiteiro] junto com outros grandes artistas do nosso tempo, disse em comunicado o diretor executivo da Julien S. Martin Nolan. A Flower Girl é o único mural no conjunto de obras que serão vendidas pela casa de leilões, em Bevely Hills na Califórnia (grifo nosso, Jornal 0 Globo 11/08/2013, caderno: Cultura).

Os segmentos de texto apresentados acima confirmam as discussões de Cartaxo (2009) e Ferreira (2011) sobre a arte urbana ter alcançado os espaços institucionalizados e ter se tornado um sinônimo de arte contemporânea com valor no mercado de arte. Cascardo (2012) também afirma que, se antes os marchand vendiam as obras de grafiteiros para quartos de crianças, hoje elas estão ao lado de Volpi e Krajcberg na casa de colecionadores. Isso mostra o grafite como uma arte que tem início nas ruas e que, através de um movimento de reconhecimento, adentra os espaços das galerias e alcança altos ganhos financeiros em um movimento ascendente. Contudo, esta faceta do grafite se destaca na mídia em detrimento das outras práticas de arte de rua, que continuam a existir e a se diversificar.

A terceira observação foca a relação entre arte-espaço-projeto. Esta associação indica que não só os grafiteiros ou os outros artistas de rua se apropriam do espaço urbano. A mídia e atores sociais de formação mais clássica em arte também reconhecem esse espaço como importante para a produção e divulgação de sua arte como pode ser visto na frase a seguir:

... após um convite para desenvolver o projeto de um piso em ladrilho hidráulico, estes artistas viram nos azulejos um bom mote para voltar a criar arte na cidade, inspirados nos painéis públicos de, entre outros, Candido Portinari e Athos Bulcão" (Grifo Iramuteq - Jornal O Globo, 22/08/2013, caderno: Cultura). 
É interessante ressaltar, porém, que embora o grafite tenha articulado grande número de movimentos sociais em comunidades da periferia e em centros urbanos, alguns projetos de reconhecimento internacional como Meeting of Favelas (MOF) e o Museu de Favelas (MUF) têm obtido pouco espaço de divulgação na mídia escrita. Segundo Santos (2010) e Rink e Will (2015a; 2015b), esta desvalorização pode ser percebida no desenvolvimento de alguns projetos. Segundo estes autores, isto ocorre por ingerência no processo criativo do direcionamento social imposto ou pela pouca divulgação de movimentos já implantados de integração com a comunidade. Para Santos (2010) e Rink e Will (2015a; 2015b), a imposição configura um paradoxo em que, ao legitimar a arte do grafite, condiciona seus autores aos interesses de quem os patrocina, num enquadramento aos moldes da cultura hegemônica. Isto sugere que a arte urbana tem sido apresentada pela mídia escrita como sinônimo de grafite, associado aos espaços fechados das galerias e com fins econômicos. Desta forma, fica evidente a nãodivulgação de projetos comunitários realizados a partir das técnicas do grafite e das diversas formas de arte de rua ou de sua capacidade na crítica social e ação política.

\section{Considerações finais}

Este estudo objetivou investigar os discursos de jornais impressos de grande circulação sobre a arte de rua e os artistas urbanos e percebendo que as mídias impressas tendem a uma generalização e simplificação dos conceitos de arte urbana ou da arte de rua como sinônimo de grafite. O grande destaque atribuído ao grafite não contempla da mesma forma seu autor, o grafiteiro. Este aparece isolado, numa relação frágil com a sua produção. $\mathrm{O}$ mesmo ocorre com relação ao espaço primeiro do grafite, o muro.

Ao quebrar a tríade grafite-grafiteiro-muro a mídia quebra também a lógica básica da comunicação da arte de rua feita pelo artista-grafiteiro em seu espaço mais utilizado, o muro. De certa forma, a mídia valoriza a cultura de elite em detrimento da cultura de massa ao valorizar o espaço das galerias e pouco se deter nos projetos sociais ou nas possibilidades de questionamento da cultura hegemônica presente na sociedade através do grafite ou das demais expressões da arte de rua. Para Canevacci (2004), as diversas formas de comunicação urbana exacerbam diferenças e possibilitam criar novos significantes. Assim, as diferenças passam a coexistir nos espaços públicos até entrarem em conflito para, finalmente, desfazer a distinção entre a cultura de elite e a cultura de massa.

Segundo Campbell e Terça-Nada! (2011), a arte constitui uma forma de criar relações com o mundo a partir de signos e objetos, e tem espaços de legitimação, quanto maior a sua divulgação e aceitação pelos diferentes atores sociais. Neste ponto, a mídia exerce um papel fundamental. Esta pesquisa evidenciou que o grafite ultrapassou a condição de simples arte urbana, tornando-se uma forma de arte contemporânea, reconhecida por arquitetos e marchand em paredes de interiores de casas e apartamentos e em galerias, abrindo um novo espaço de trabalho e de reconhecimento. No entanto, constata-se que os interesses hegemônicos prevalecem sobre os potenciais de questionamentos sociais e políticos desta forma de arte. Embora essa aproximação da cultura hegemônica ao grafite possa atribuir-lhe aspectos positivos como a passagem da arte de rua para as galerias, expressa também uma limitação das possibilidades de articulação social e política desta forma de arte. 
Apesar de ficar evidenciada uma forma de divulgação fragmentada sobre arte urbana pela mídia, observa-se a profissionalização dos artistas de rua e, em especial, dos grafiteiros ao longo dos anos e o crescente reconhecimento pela sociedade. Movimentos importantes de articulação cultural e social como o MOF (Meeting of Favela) que acontece anualmente na Vila Operária em Duque de Caxias e o MUF (Museu de Favelas) sediado nas Favelas Pavão, Pavãozinho e Cantagalo, têm pouco espaço na mídia escrita e boa parte da divulgação do trabalho dos grafiteiros e demais artistas de rua ocorre por iniciativa própria dos mesmos através das redes sociais (Cruz, 2014). Ou seja, embora os movimentos de arte urbana estejam cada vez mais presentes em nossa sociedade, interferindo e transformando o contexto social, o espaço dado pela mídia para estes movimentos é escasso, visto o pequeno número de artigos veiculados ao longo de um ano. Assim, a arte de rua que, em tese, dá voz a muitos indivíduos e possibilita novas discussões sobre os direitos sociais e políticos, fica emudecida na falta de um espaço de reconhecimento e divulgação pela mídia.

\section{Referências}

Azoulay, A. (2011). Getting Rid of the Distinction Between the Aesthetic and the Political. Theory, Culture \& Society, (27), 239-262.

Bardin, L. (2006). Análise de conteúdo. Lisboa, Edições 70.

Blauth, L. \& Possa, A. C. K. (2012). Arte, grafite e o espaço urbano. Palíndromo, Programa de Pós-Graduação em Artes Visuais, CEART/UDESC, 4(8). Retirado de http://www.revistas.udesc.br/index.php/palindromo/article/view/3458/2479.

Camargo, B. V. \& Justo, A. M. (2013). IRAMUTEQ: um software gratuito para análise de dados textuais. Temas em Psicologia,21(2), 513-518. Retirado de http://pepsic.bvsalud.org/pdf/tp/v21n2/v21n2a16.pdf.

Camino, L. (1996). Uma abordagem psicossociológica no estudo do comportamento político. Psicologia e Sociedade, 8,16-42.

Campbell, B. \& Terça-Nada!, M. (2011). Intervalo, respiro, pequenos deslocamentos: ações poéticas do poro. Primeira edição. São Paulo: Radical Livros.

Canevacci, M. (2004). A cidade Polifônica - ensaio sobre antropologia da comunicação urbana. Segunda edição. São Paulo: Studio Nobel.

Cartaxo, Z. (2009). Arte nos espaços públicos: a cidade como realidade. UNIRIO, 1(1). Retirado de http://www.seer.unirio.br/index.php/opercevejoonline/article/view/431/381.

Carvalho Neto, M. B., Alves, A. C. P., \& Baptista, M. Q. G. (2007). A “consciência” como um suposto antídoto para a violência. Revista Brasileira de Terapia Comportamental e Cognitiva, 9(1), 27-44.

Cascardo, A. B. S. (2012). Grafite contemporâneo: da espontaneidade urbana à sua cooptação pelo mundo da arte. Musear, 1(1), 1-17. Retirado de http://www.museologia.ufop.br/musear/wp-content/uploads/2012/06/9Grafite-contempor\%C3\%A2neo-da-espontaneidade-urbana-\%C3\%A0-sua-coopta\%C3\%A7\%C3\%A3o-pelomundo-da-arte.pdf.

Costa Junior, H. G. \& Portinari, D. B. (2014). Estética política: sobre grafite e subjetividade na América Latina. Sures, 3, 1-14. Retirado de https://revistas.unila.edu.br/index.php/sures/article/view/160/135

Cruz, E. G. G. (2014). Grafite como prática de letramento: o muro e seus escritos. Trabalho de Conclusão de Curso apresentado ao Colegiado de Letras Vernáculas, Instituto de Letras, Universidade Federal da Bahia - UFBA, Salvador, Bahia, Braisl. Retirado de https://repositorio.ufba.br/ri/bitstream/ri/17126/1/TCC\%20- 
\%20Evanilton\%20Gon\%C3\%A7alves.pdf.

Csikszentmihalyi, M. (1996). Creativity: flow and the psychology of discovery and invention. Segunda edição. New York, NY: Harper Collins.

De Certeau, M. (1998). A Invenção do Cotidiano. Terceira edição. Petrópolis, RJ: Vozes.

Deschamps, J. C. \& Devos, T. (1993). Valeurs, cultures et changement. Intercultures, 1, 17-28.

Fernandes, S. C. S. (2009). Sentimentos em relação à política à luz dos valores e do preconceito social. Opinião Pública, 15(1), 224-246.

Ferreira, M. A. (2011). Arte Urbana no Brasil: expressões da diversidade contemporânea. VIII Encontro nacional da História da Mídia, Unicentro, Guarapuava, PR, ISSN 15801780.

Ferreira, S. \& Travancas, I. (2014). Antropologia da mídia: um campo em construção no Brasil e em Portugal. Revista FAMECOS - mídia, cultura e tecnologia, 21(2), 622-646. Retirado de http://revistaseletronicas.pucrs.br/ojs/index.php/revistafamecos/article/viewFile/15729/11809.

França, S. A. M. (2012). Cidades Feitas de Gestos. In L. A. Baptista \& M. S. Ferreira, M. S. (Org). Por que a cidade? Escritos sobre experiência urbana e subjetividade (pp. 199-217). Niterói: Editora da UFF.

Franco, S. (2013). Pixação e memória: a cidade como lápide. In A. E. Leite (Org.). Graffiti em São Paulo - tendências contemporâneas (pp. 172-189). Botafogo, RJ: Aeroplano.

Furtado, J. R. \& Zanella, A. V. (2009). Graffiti e cidade: sentidos da intervenção urbana e o processo de constituição dos sujeitos. Revista Mal-estar e Subjetividade, 9(4), 1279-1302.

Guareschi, P. A. (2007). Mídia e democracia: o quarto versus o quinto poder. Dossiê mídia e política, Revista Debates, Porto Alegre, 1(1), 6-25. Retirado de http://seer.ufrgs.br/debates/article/view/2505.

Guattari, F. (2006). Caosmose: Um novo paradigma estético. Quarta reimpressão. Jardim Botânico, RJ: Editora 34.

Guimarães, C. (2008). Jornalismo Desmanchado no ar: o fragmento como método no discurso pós-moderno. Dissertação de Mestrado, Universidade Federal do Rio de Janeiro, RJ, Brasil.

Harvey, D. (2013). A Liberdade da Cidade. In Vainer, C; Harvey, D; Maricato, Brito, F; Peschanski, J. A; Maior, J. L. S; Secco, L; Iasi, M. L.; Ninja, M; Davis, M; Movimento Passe Livre; Oliveira, P. R; Rolnik, R.; Braga, R; Viana, S; Žižek, S \& Lima, V. A. Cidades Rebeldes - passe livre e as manifestações que tomaram as ruas do Brasil (pp. 31-39). São Paulo, SP: Boitempo.

Marchand, P. \& Ratinaud, P. (2012). L'analyse de similitude appliqueéaux corpus textueles: lês primairessocialistespourl'electionprésidentiellefrançaise. In Actesdes 11eme Journéesinternationalesd'Analysestatistique des Données Textuelles. JADT, pp. 687-699. Liège, Belgique. Retirado de http://lexicometrica.univparis3.fr/jadt/jadt2012/Communications/Marchand,\%20Pascal\%20et\%20al.\%20\%20L\%27analyse\%20de\%20similitude\%20appliquee\%20aux\%20corpus\%20textuels.pdf

Marcuse, H. (2009). A responsabilidade da ciência. Scientiae Studia, 7(1), 159-164. (Trabalho original publicado em 1966).

Maturana, H. (2002). Emoção e Linguagem na Educação e na Política. Terceira reimpressão. Belo Horizonte, MG: UFMG.

Mesquita, A. L. (2006). Arte-ativismo: Interferência, coletivismo e transversalidade. Linguages, 1-10. Retirado de https://exerciciodacritica.files.wordpress.com/2009/05/arteativismo1.pdf

Moura, T. S. R. (2014). Pixadores, grafiteiros e suas territorialidades: apropriações socioespaciais na cidade do Recife. Dissertação de Mestrado, Universidade Federal de Pernambuco, Recife, Pernambuco, Brasil. Retirado de

http://repositorio.ufpe.br/bitstream/handle/123456789/11068/DISSERTA\%C3\%87\%C3\%830\%20Thiago\%20 Santa\%20Rosa\%20de\%20Moura.pdf?sequence=1\&isAllowed=y.

Negri, A. \& Cocco, G. (2005). Glob(Al): Biopoder e luta em uma América Latina globalizada. Rio de Janeiro e São 
Paulo: Record.

Ortega, F. (2000). Para uma política da amizade: Arendt, Derrida, Foucault. Rio de Janeiro: Relume Dumará.

Paim, D. C., Machado, R. O., Scarparo, H. B. K. \& Pizzinato, A. (2013). Luzes, câmera... Ação! No ar, a transformação midiática do conceito de periferia no conceito de comunidade. Estudos e pesquisa em Psicologia, Rio de Janeiro, 13(3), 835-854.

Raposo, P. (2013). Terra do Não Lugar a Diálogos entre Antropologia e Performance. Florianópolis: UFSC.

Ratinaud, P. (2009). IRAMUTEQ: Interface de R pourles Analyses Multidimensionnelles de Textes et de Questionnaires [Computer software]. Retirado de http://www. iramuteq.org.

Rink, A. \& Will, S. V. (2015a). O grafite como movimento de resistência e sua captura pelas tecnologias educacionais. In Paula, M. F. C. (Org.). Políticas de Controle Social, Educação e Produção de Subjetividade (pp. 317-337). Florianópolis: Insular.

Rink, A. \& Will, S. V. (2015b). Grafite e sua captura pelas tecnologias educacionais. In: Convibra - Management, Education and Health Promotion Conference Congress. Retirado de http://www.convibra.org/upload/paper/2015/59/2015_59_11926.pdf

Rink, A. (2013). Graffiti: Intervenção Urbana e Arte. Curitiba: Appris.

Rosanvallon, P. (2008). La Légitimité Démocratique. Paris: Seuil.

Salles, M. (2008). Comunicação e Controle Social. Classe: Revista de Política e Cultura, 1(20), 53-55. Retirado de http://www.aduff.org.br/publicacoes/200812_classe_2.pdf.

Santos, B. S. (2002). Um discurso sobre as ciências. Porto: Afrontamento.

Santos, T. M. (2010). Grafite: a leitura dos muros. In VI Enecult (Encontro de estudos multidisciplinares em cultura), 1-13. Retirado de http://www.cult.ufba.br/wordpress/24406.pdf.

Spinelli, L. (2010). Um olhar brasileiro sobre uma abordagem etnográfica do grafite português. Visualidades, 8(2), 345-349. Recuperado de https://revistas.ufg.emnuvens.com.br/VISUAL/article/viewFile/18292/10928.

Vigotski, L. S. (2011). A Formação Social da Mente. Sétima edição. São Paulo, SP: Martins Fontes.

Will, S. V. (2015). Vigiar, Punir, Educar e Matar: Discursos de disciplinamento, controle e extermínio da população preta e pobre do Rio de Janeiro. Tese de doutorado, Universidade Federal Fluminense, Niterói, RJ, Brasil.

Zago, G.O. (2008). Twitter como Suporte para Produção e Difusão de Conteúdos Jornalísticos. In: 6o Encontro Nacional de Pesquisadores em Jornalismo. São Bernardo do Campo, SP, Brasil: SBPJor.

Apresentação: 12/07/2016

Aprovação: 29/11/2016 